\section{Clinital gDepartment.}

\section{THE CON'TAGIOUSNESS OF ERYSIPELAS.}

BX WALTEle RIED,

Assistant Surgeon U.S. A., Fort Snelling, Minn.

In the Journal of February 4, 1892, Prof. J. C. White, of Harvard, writing concerning "Some Dangers of Infection Incidental to Professional Life," says: "With regard to the contagious character of erysipelas diverse opinions prevail." Again : "Common belief has it that there is great danger of such communication, an opinion largely held apparently by our profession as well. I do not doubt the possibility of such trans. ference, but I believe that it rarely occurs; I refer to the ordinary superficial forms of the affection. In the great number of cases that 1 have treated I have not known a single instance in which a second member of the family, a nurse, or medical attendant has become affected."

As I have had an experience bearing directly upon the point at issue, I beg to submit it. During the fall of 1883, Lieutenant B. was attucked with facial erysipelas of a moderately severe type, the-disease commencing over the bridge of the nose and spreading rapidly over the face and scalp. He was carefully nursed by Private A., who remained the greater part of the time in the room with him, and who slept in an adjoining room.

About the time Lieutenant B. was convalescent some twenty days from the beginning of the attack - Private $A$. becume engaged in an altercation and received a contused wound over the left orbit. This wound was dressed by the writer, the day following its receipt. 'The next day erysipelas appeared in the edges of the wound, rapidly extending to scalp and lower face. Now, I will admit that it would be perfectly fair to conclude that Private A. had probably infected his wound with the streptococcus pyogenes, which had remained on his fingers since his attendance on Lieutenant B., or that the writer had infected the wound; for we had both repeatedly applied cloths to the erysipelatous surface of the first patient.

However, be this as it may, Private A. was placed in a room by himself at the post hospital, and Hospital Attendant $K$. detailed to nurse him. Although this man did not sleep in the room, he virtually occupied it the greater part of the time, as the patient was troublesome and required almost constant attention.

'Three weeks later, while A. was convalescing, Hospital $\Lambda$ ttendant $K$. was attucked with facial erysipelas and was put to bed in the same room with the second case, and Private S. detailed to nurse hin.

Before Attendant K. had recovered fairly, Private S. was stricken down with the same disease and was placed in a separate room. He was nursed by Acting Hospital Steward G., who volunteered his services for this purpose. He was told that he need not remain in the room any more than was absolutely necessary to look ufter the wants of the patient, but as the steward had no fear of the disease, he was constantly in attendance, and spent a part of each night with tho sick man.

When the foregoing cases had recovered, the two rooms were thoroughly disinfected, walls and floors being wiped down with bichloride solution, and afterwards exposed to fumes of burning sulphur.

'Three weeks from the commencement of Private
S.'s case, which had not been severe, Acting Steward G. was attacked with facial erysipelas of a very severe type, and came near dying.

As there seemed to be no end to this succession of cases transmitted from patient to attendant, I requested the detail of four men to nurse this latter case; each man to be on duty six hours, and during this time to remain in the room as little as possible; free ventila. tion of the room to be enforced, and while off duty to remain in the open air as much as possible. Under this system of nursing, our little epidemic onded.

'Thore had been no cases of erysipelas at the station prior to Lieutenant B.'s case, and none occurred during the following seven months of my stay at the post. I believe that the second patient would have had the dis. ease, oven had he not suffered any traumatism. I think that this conclusion is perfectly justifiable in the light of the occurrence of the subsequent cuses, without any break in the integument. I know not how the streptococcus pyogenes gained access to the circulation of those patients. Each case began with soreness and congestion of the pharyux with some swelling of the lymphatics of the neck. 'This was slight and soon subsided. 'There was no formation of abscesses beneath the skin, except in the last case, in the loose tissue around the left orbit. All were young men in the prime of life.

Looking at the matter from my standpoint, I should say that there is good cause for the common belief that erysipelas can be communicated from patient to atteudaut.

\section{TWO OVARIO'TOMIES.}

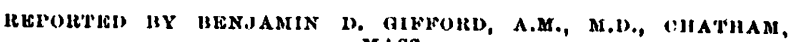
MA88.

Two cases of ovarian cysts which came under my observation during the second week in December, 1891, for the removal of which laparotomies were performed, illustrate in a remarkable manner the value of this operation, not only when undertaken for the deliberate cure of the affection, but also as a means of saving life when the couditions appear unfavorable and the patient evidently about to die.

'The first case, that of Mrs. II., age thirty-six, childless, was one in which peritonitis was present and chreatened life. She had been to Boston and had unlergone a somewhat rough handling in the repeated examinations which she had received in a public clinic, and after a ride of nearly one hundred miles home was taken with a chill, which developed a peritonitis. This was of an active type, generally diffused and sufficiently severe to call for the gravest apprehensions for her recovery. Under the circumstances I ad. vised an operation as the meaus best calculated to give her a chance for life. Accordingly I telegraphed for Dr. Henry O. Marcy, of Boston, who came down and operated. 'The tumor, which weighed sixteen or eighteen pounds, was located on the left side and was every where adherent, both to the abdominal walls and to portions of the intestines by recent lymph. The most noticeable thing about it was the fact that the tumor had been completely twisted upon its pedicle, and the entire growth external to the constricted neck of the cyst was gangrenous. The pediclo was sewed across with kangaroo tendon, and a sufficient amount of peritoneum was dissected from it to be intra-folded over the stump, and was secured by a continued Lem. 